\title{
Translocation (1;22)(p36;q11.2) with concurrent del(22)(q11.2) resulted in homozygous deletion of SNF5/NI1 in a newly established cell line derived from extrarenal rhabdoid tumor
}

Received: 21 June 2004 / Accepted: 23 July 2004/Published online: 18 September 2004

(C) The Japan Society of Human Genetics and Springer-Verlag 2004

\begin{abstract}
Malignant rhabdoid tumor (MRT) is a highly malignant pediatric cancer, which arises in various sites such as the kidney, brain, and soft tissues. Cytogenetic studies have revealed alterations of 22q11 in MRT. Recently, deletions and mutations of the SNF5/INII locus in 22q11.2 have been reported in MRT, suggesting that $S N F 5 / I N I 1$ is a tumor suppressor gene for MRT. Here we report our molecular cytogenetic study for a newly established cell line from extrarenal MRT with $\mathrm{t}(1 ; 22)(\mathrm{p} 36 ; \mathrm{q} 11.2)$. Consequently, the reciprocal translocation was associated with the interstitial deletion of a small segment including SNF5/INI1, and another, chromosome 22, showed terminal deletion, the breakpoint of which was located $70-80 \mathrm{~kb}$ centromeric to SNF5/INI1, resulting in homozygous deletion of SNF5/ INII in this cell line.
\end{abstract}

Keywords Malignant rhabdoid tumor ·

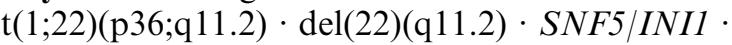

Homozygous deletion

\footnotetext{
A. Misawa $\cdot$ I. Imoto $\cdot$ J. Inazawa $(\square)$

Department of Molecular Cytogenetics,

Medical Research Institute and Graduate School of Biomedical

Science, Tokyo Medical and Dental University,

1-5-45 Yushima, Bunkyo-ku, Tokyo 113-8510,

Japan

E-mail: johinaz.cgen@mri.tmd.ac.jp

Tel.: + 81-3-58035820

Fax: $+81-3-58030244$

A. Misawa $\cdot$ I. Imoto $\cdot$ J. Inazawa

Core Research for Evolutionary Science and Technology,

Japan Science and Technology Corporation,

Kawaguchi, Japan

H. Hosoi $\cdot$ T. Iehara $\cdot$ T. Sugimoto

Department of Pediatrics,

Kyoto Prefectural University of Medicine,

Kyoto, Japan

J. Inazawa

Center of Excellence Program for Frontier Research on Molecular

Destruction and Reconstitution of Teeth and Bone,

Tokyo Medical and Dental University, Tokyo, Japan
}

\section{Introduction}

Malignant rhabdoid tumor (MRT) is a rare and highly aggressive cancer that occurs in very young children (Parham et al. 1994). This type of tumor can occur in various locations but mainly in the kidney, brain, and soft tissues. The cell of origin remains unknown. Genetic abnormalities such as partial deletions and translocations involving 22q11.2 have been described in several cases of MRT. Subsequently, the chromatin-remodeling SNF5/INI1 gene at 22q11.2 was isolated as a tumor suppressor gene in MRT (Versteege et al. 1998). On the other hand, molecular studies have shown a relatively high rate of loss of heterozygosity $(\mathrm{LOH})$ in many human cancers, including neuroblastoma in chromosome band $1 \mathrm{p} 36$, suggesting the presence of unknown tumor suppressor genes in this region. Here we report our molecular cytogenetic study for an established cell line of extrarenal MRT carrying $\mathrm{t}(1 ; 22)(\mathrm{p} 36 ; \mathrm{q} 11.2)$ concurrent with del(22)(q11.2), which resulted in homozygous deletion of SNF5/INII.

\section{Case report}

A 5-month-old boy was found to have a thoracic mass (Fig. 1) without metastasis at the time of diagnosis. The tumor was totally resected. The histopathologic analysis demonstrated that the cells were round in shape with vesicular nuclei, prominent nucleoli, and no typical eosinophilic cytoplasmic inclusions. The cells stained positive for vimentin and negative for desmin by immunohistochemistry. Expression of MyoD, PAX3FKHR, EWS-FLI1, EWS-ERG, and SSX-SYT chimeric mRNA was absent in the tumor. Analysis of G-banded preparations of the tumor showed only a terminal deletion of 22q. Spectral karyotyping (SKY) analysis combined with DAPI banding method from the primary tumor tissue demonstrated $\mathrm{t}(1 ; 22)(\mathrm{p} 36 ; \mathrm{q} 11.2)$ (Fig. 2). The patient received four cycles of doxorubicin, 
vincristine, and cyclophosphamide, alternating with ifosfamide and etoposide. However, after 18 months off-therapy, local recurrence was detected. He then received a total resection, additional chemotherapy, and 30.6-Gy radiation therapy. No further recurrence has been observed. Currently, he is alive and well at 4 years post onset. Cytogenetic analysis of his peripheral lymphocytes revealed a normal male karyotype.

\section{Materials and methods}

Cell lines The surgical specimen of the tumor was minced in RPMI 1640 medium containing $10 \%$ fetal bovine serum and penicillin-streptomycin at $37^{\circ} \mathrm{C}$ in a $5 \% \mathrm{CO}_{2}$ incubator. The medium was changed twice a week. Cells were subcultured into new flasks by trypsinization when cultures were in a subconfluent state and the tumor cell line, designated KP-MRT-YM, was established. The biological and other molecular characteristics of this cell line will be described elsewhere. Human rhabdomyosarcoma cell lines, RD and KYM-1, were from the Japanese Collection of Research Bioresources Cell Bank (Osaka, Japan).

Spectral karyotyping (SKY) Spectral karyotyping (SKY) analysis was performed using SkyPaint probe mixture (Applied Spectral Imaging, Carlsbad, CA, USA) according to the manufacturer's protocol (Ariyama et al. 1998).

Fluorescence in situ hybridization (FISH) Metaphase chromosome slides were prepared for fluorescence in situ hybridization (FISH) experiments. The location of each BAC (RPCI-11) within the region of interest was archived by the database of UCSC (http://genome.ucsc.edu) or NCBI (http://www.ncbi.nlm.nih.gov). A total of 13 BAC contigs representing the regions of interest at 22q11.23 (BACs 22M5, 24N11, 659D9, 22L18, 69B15, 61N10, 248J22, 61P17, 71G19, 124F9, $759 \mathrm{G} 12,76 \mathrm{E} 8$, and $325 \mathrm{G} 5$ ) and six BAC contigs representing the regions of interest at $1 \mathrm{p} 36.11$ (1114G7, 23D20, 65E18, 229A14, 111D20, and 96L14) were used as probes (Fig. 3). We confirmed the mapping data according to the results of FISH using normal metaphase chromosomes. Probes were labeled with biotin-16dUTP or digoxigenin-11-dUTP by nick-translation (Roche Diagnostics, Tokyo, Japan). The copy number and molecular organization of the region were assessed according to the hybridization patterns observed on both metaphase and interphase chromosomes.

Genomic PCR DNA was extracted from the established tumor cell line. Genomic PCR of SNF5/INI1 exon 6 was performed using FastStart Taq (Roche Diagnostics) with primers (forward primer, 5'-AGCATGGTGCAATCTCTTG-3'; reverse primer, 5'-GGCTTCTGCTGAGGCCTT-3') according to the manufacturer's protocol: denaturing at $94^{\circ} \mathrm{C}$ for $5 \mathrm{~min}$ was followed by

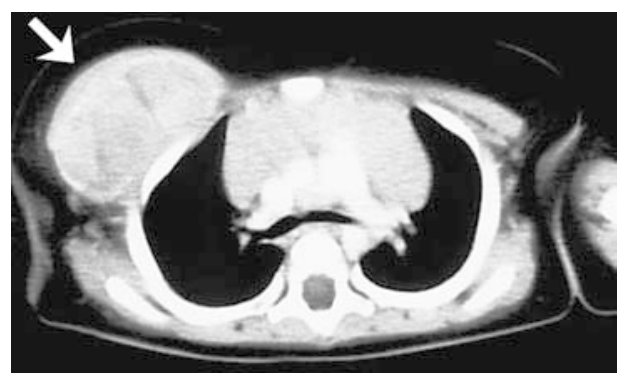

Fig. 1 Computed tomography scan showed an enhanced thoracic mass

32 cycles of amplification $\left(94^{\circ} \mathrm{C}\right.$ for $30 \mathrm{~s}, 58^{\circ} \mathrm{C}$ for $30 \mathrm{~s}$, $72^{\circ} \mathrm{C}$ for $1 \mathrm{~min}$ ) and $7 \mathrm{~min}$ of extension at $72^{\circ} \mathrm{C}$. The PCR products were electrophoresed on $2.0 \%$ agarose gels.

$R T$ - $P C R$ Single-strand cDNAs were generated from the total RNAs of cell lines using the SuperScript FirstStrand Synthesis System (Invitrogen, Carlsbad, CA, USA) according to the manufacturer's directions. RTPCR was performed using FastStart Taq: denaturing at $94^{\circ} \mathrm{C}$ for $5 \mathrm{~min}$ was followed by 30 cycles of amplification $\left(94^{\circ} \mathrm{C}\right.$ for $30 \mathrm{~s}, 64^{\circ} \mathrm{C}$ for $30 \mathrm{~s}, 72^{\circ} \mathrm{C}$ for $\left.1 \mathrm{~min}\right)$ and $7 \mathrm{~min}$ of extension at $72^{\circ} \mathrm{C}$. The primers used for amplification of $S N F 5 / I N I 1$ sequences from exons 1 to 6 were 5'-CTGAGCAAGACCTTCGGGCAG-3' (forward) and 5'-GATGGCTGGCACAAACGTCAG-3' (reverse).

\section{Results and discussion}

Conventional cytogenetic and SKY analysis of the fresh tumor demonstrated a cryptic aberration of $\mathrm{t}(1 ; 22)$ (p36;q11.2) in addition to del(22)(q11.2) (Fig. 2). In order to clarify the translocation breakpoints involved in chromosomes 1 and 22, we performed FISH analysis of the established KP-MRT-YM cell line using BACs as probes (Fig. 3). The breakpoint on $\operatorname{der}(22) \mathrm{t}(1 ; 22)$ was found to lie proximal to the BAC 22L18 and distal to the BAC 24N11. We also confirmed that der(22) was involved in the interstitial deletion of a small segment between BAC 22L18 and 124F9 within 22q11.22-23, estimated to be $1.6 \mathrm{Mb}$ including SNF5/INI1 gene. In addition, del(22) showed terminal deletion proximal with a break at 22q11 between $61 \mathrm{P} 17$ and $71 \mathrm{G} 19$. The breakpoint was located approximately $70-80 \mathrm{~kb}$ centromeric to $S N F 5 / I N I 1$. We could not detect any fluorescent signal corresponding to BACs harboring SNF5/INI1, $71 \mathrm{G} 19$ and 124F9 (Fig. 3C). Taken together, the homozygously deleted region spanned approximately $66 \mathrm{~kb}$ of the genomic sequence and included four known genes, such as VPREB3, MMP11,SLC2A11, and MIF, other than SNF5/INI1. Among those, only SNF5/INI1 has been reported to play a critical role in tumorigenesis of MRT so far as we know.

In PCR analysis, we used rhabdomyosarcoma cell line RD and KYM-1 as positive and negative controls 


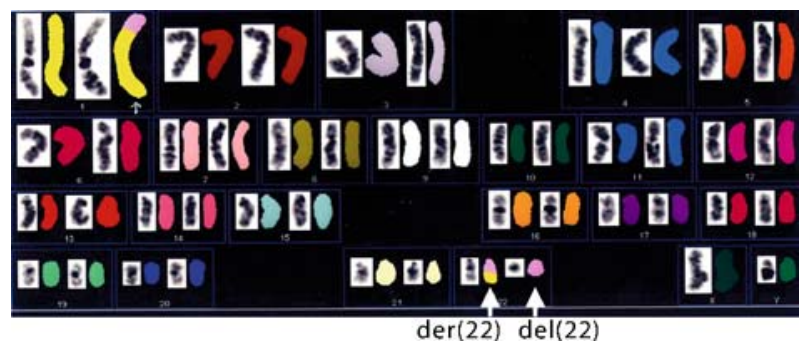

Fig. 2 Spectral karyotyping (SKY) analysis of the fresh tumor demonstrated $\mathrm{t}(1 ; 22)(\mathrm{p} 36 ; \mathrm{q} 11.2)$

(Uno et al. 2002) for $S N F 5 / I N I 1$, respectively. As shown in Fig. 4A, genomic PCR unambiguously showed homozygous deletion of exon 6 in KP-MRT-YM as well as in KYM-1. Expression of the SNF5/INI1 gene was not detected by RT-PCR (Fig. 4B), which confirmed the homozygous deletion of both SNF5/INII alleles in KP-MRT-YM.

Fig. 3 A Map of 22q11 region and schematic representation of cytogenetic and molecular data on KP-MRT-YM cell line. Each vertical line represents the parental chromosomes. Contig BACs are mapped on the right of the vertical chromosome. Open square present FISH signals, filled square absent signals, open circle located signals on der(1). A closed arrow indicates the region involved in a homozygous deletion. B,C FISH analysis of KPMRT-YM cell line. B 23D20, located in 1p36.11; probe is shown in red. These signals were detected on the normal 1 and $\operatorname{der}(22)$, demonstrating $\mathrm{t}(1 ; 22)$. 76E8, located distal to $S N F 5 / I N I 1$ in 22 q11.23; probe is shown in green and was observed on only der(1) but not on chromosome 22 . C $24 \mathrm{~N} 11$, located proximal to SNF5/INI1 in 22q11.23; probe is shown in red. 71G19, containing the SNF5/INI1 gene; probe is labeled in green and was not detected in the KP-MRT-YM cell line, although the signals could clearly be seen in the normal chromosome. Genomic information was obtained from UCSC (http://genome.ucsc.edu) and NCBI (http:// www.ncbi.nlm.nih.gov)
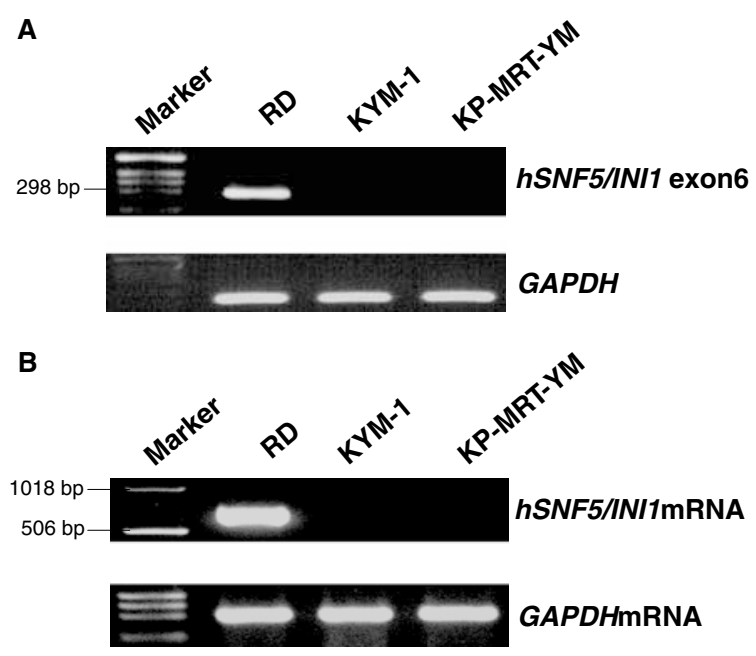

Fig. 4 A Genomic PCR of $S N F 5 / I N I 1$ exon 6. GAPDH primers were used as an internal control. B RT-PCR analysis for $S N F 5 /$ INII. GAPDH primers were used as an internal control

On chromosome 1, the translocation breakpoint was determined to map on the overlapping region of the BACs 65E18 and 229A14 and was evaluated to be approximately $62 \mathrm{~kb}$ within $1 \mathrm{p} 36.11$ (Fig. 5). The region included three predicted genes (LOC56181, MGC2603, and FJL32206), although no biological function of each has been clarified yet.

To our knowledge, only two cases of rhabdoid tumor with $\mathrm{t}(1 ; 22)(\mathrm{p} 36 ; \mathrm{q} 11.2)$ have been described in the literature (Rosty et al. 1998; Rousseau-Merck et al. 1999; Simons et al. 1999). One of the cases arose in the lung and the other in the chest wall. Both patients died due to progression of the disease, whereas our case has
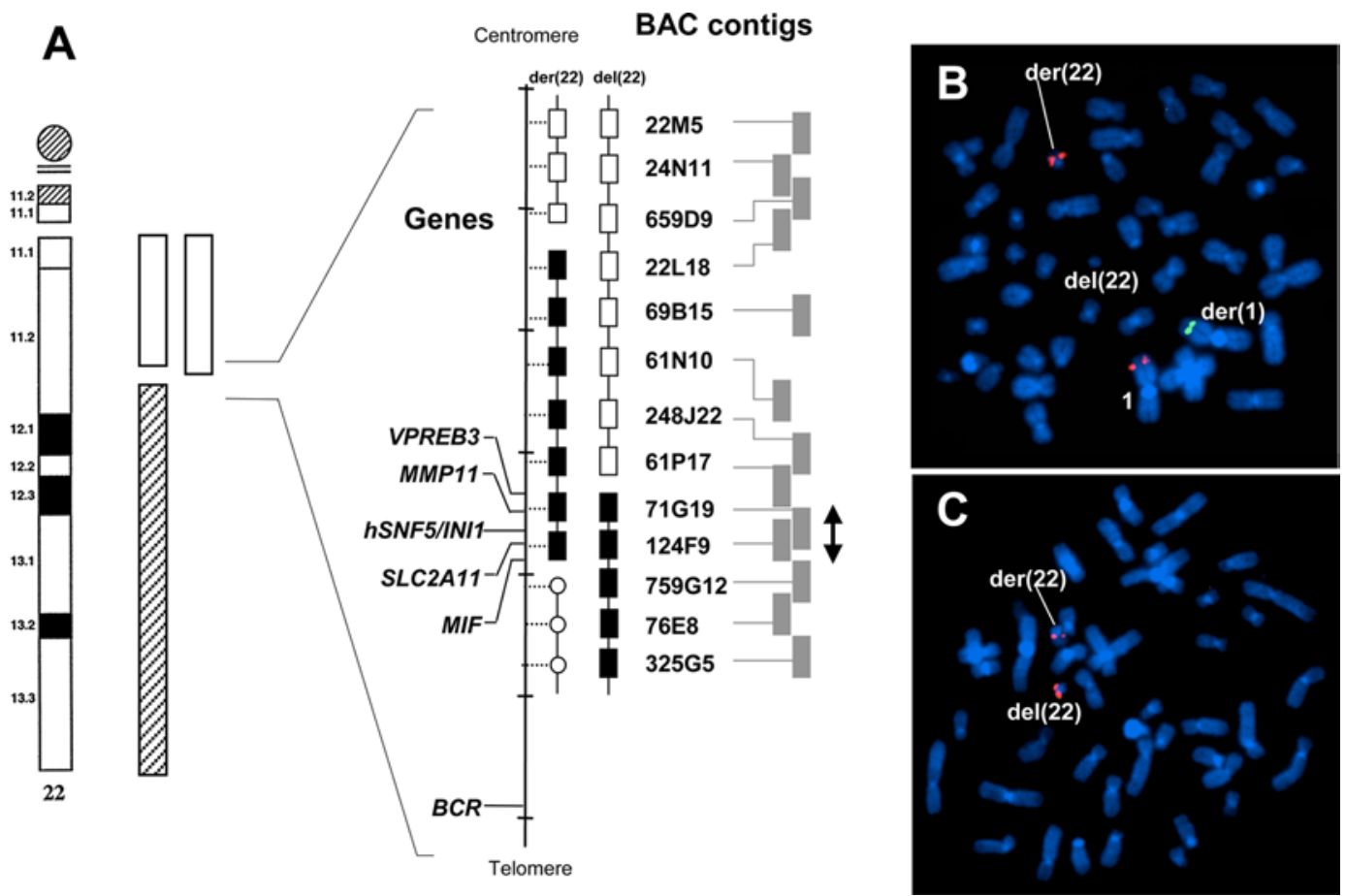


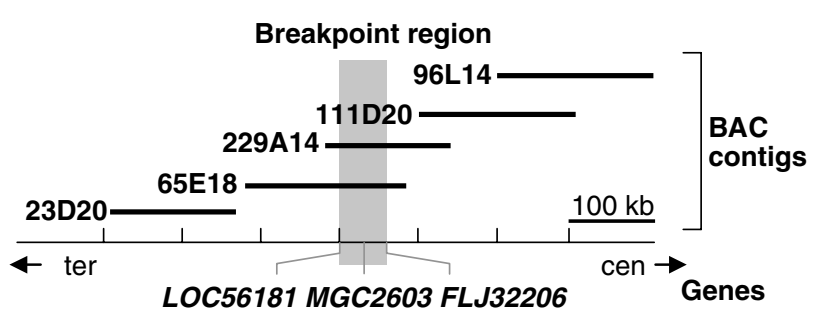

Fig. 5 Map of 1 p36 region. The breakpoint was determined by fluorescence in situ hybridization (FISH) analysis of KP-MRT-YM cell line

achieved 1.5-year disease-free survival after the second surgery. In our case, the translocation breakpoint was mapped on the overlapping region of the BACs 65E18 and 229A14 and was evaluated to be approximately $62 \mathrm{~kb}$ within $1 \mathrm{p} 36.11$. The breakpoint reported by Rosty et al. was differently from that in the present case, located $14 \mathrm{Mb}$ telomeric to the 65E18. All three patients, in the previous cases and the present case, without metastatic disease had different prognoses, which may be related to the different breakpoints. It is unlikely that a common functional fusion gene product was generated, although the rearrangement may inactivate a tumor suppressor gene.

The chromatin-remodeling SNF5/INII gene at $22 \mathrm{q} 11.2$ has been reported as a tumor suppressor in MRT (Versteege et al. 1998). Extrarenal MRT is often misdiagnosed as other types of poorly differentiated neoplasms (Biegel et al. 2002a,b) because of the heterogeneity of its histologic and immunologic features. Alterations of the SNF5/INI1 gene are restricted to MRT in pediatric solid tumors (Uno et al. 2002). In our case, cytogenetic studies of the tumor and the cell line derived from the tumor revealed a diagnosis of rhabdoid tumor, although the pathological diagnosis was undifferentiated sarcoma. Homozygous deletions of the SNF5/INI1 gene are most frequently seen in extrarenal MRT, whereas truncating mutations are detected in a high percentage of kidney and brain tumors (Biegel et al. $2002 \mathrm{a}, \mathrm{b})$. Thus, the analysis of $S N F 5 / I N I 1$ genetic status is useful for diagnosis of MRT. The SNF5/INI1 gene is a member of the SWI/SNF chromatin-remodeling complex and therefore plays a critical role in transcriptional regulation. Although the function of $S N F 5 / I N I I$ remains largely unknown, one of the mechanisms by which SNF5/INI1 exerts its tumor suppressor function has been reported as mediation of cell-cycle arrest due to the direct recruitment of histone deacetylase activity to the cyclin D1 promoter (Zhang et al. 2002). Further studies are needed for the use of specific targeted biological agents in the treatment of MRT, which is well known to be an intractable pediatric tumor.

Acknowledgements Grant support: grants-in-aid for Scientific Research on priority areas (C) and the Center of Excellence Program for Research on molecular destruction and reconstruction of tooth and bone from the Ministry of Education, Culture, Sports, Science, and Technology, Japan; and a grant-in-aid from Core Research for Evolutionary Science and Technology of the Japan Science and Technology Corporation.

\section{References}

Ariyama Y, Sakabe T, Shinomiya T, Mori T, Fukuda Y, Inazawa J (1998) Identification of amplified DNA sequences on double minute chromosomes in a leukemic cell line KY821 by means of spectral karyotyping and comparative genomic hybridization. $\mathbf{J}$ Hum Genet 43:187-190

Biegel JA, Kalpana G, Knudsen ES, Packer RJ, Roberts CWM, Thiele CJ, Weissman B, Smith M (2002a) The role of INII and the SWI/SNF complex in the development of rhabdoid tumors: meeting summary from the workshop on childhood atypical teratoid/rhabdoid tumors. Cancer Res 62:323-328

Biegel JA, Tan L, Zhang F, Wainwright L, Russo P, Rorke LB (2002b) Alterations of the $h S N F 5 / I N I 1$ gene in central nervous system atypical teratoid/rhabdoid tumors and renal and extrarenal rhabdoid tumors. Clin Cancer Res 8:3461-3467

Parham DM, Weeks DA, Beckwith JB (1994) The clinicopathologic spectrum of putative extrarenal rhabdoid tumours. Am J Surg Pathol 18:1010-1029

Rosty C, Peter M, Zucman J, Validire P, Delattre O, Aurias A (1998) Cytogenetic and molecular analysis of a $\mathrm{t}(1 ; 22)(\mathrm{p} 36 ; \mathrm{q} 11.2)$ in rhabdoid tumor with a putative homozygous deletion of chromosome 22. Genes Chromosomes Cancer 21:82-89

Rousseau-Merck MF, Versteege I, Legrand I, Couturier J, Mariral A, Delattre O, Aurias A (1999) $h S N F 5 / I N I 1$ inactivation is mainly associated with homozygous deletions and mitotic recombinations in rhabdoid tumors. Cancer Res 59:3152-3156

Simons J, Teshima I, Zielenska M, Edwards V, Taylor G, Squire J, Thorner P (1999) Analysis of chromosome 22q as an aid to the diagnosis of rhabdoid tumor. Am J Surg Pathol 23:982-988

Uno K, Takita J, Yokomori K, Tanaka Y, Ohta S, Shimada H, Gilles FH, Sugita K, Abe S, Sako M, Hashizume K, Hayashi Y (2002) Aberrations of the $h S N F 5 / I N I 1$ gene are restricted to malignant rhabdoid tumors or atypical teratoid/rhabdoid tumors in pediatric solid tumors. Genes Chromosomes Cancer $34: 33-41$

Versteege I, Sevenet N, Lange J, Rousseau-Merck MF, Ambros P, Handgretinger R, Aurias A, Delattre O (1998) Truncating mutations of $h S N F 5 / I N I 1$ in aggressive paediatric cancer. Nature 394:203-206

Zhang ZK, Davies KP, Allen J, Zhu L, Pestell RG, Zagzag D, Kalpana GV (2002) Cell cycle arrest and repression of cyclin D1 transcription by INI1/hSNF5. Mol Cell Biol 22:5975-5988 